\title{
THE MANAGEMENT OF HEAD INJURIES
}

\author{
P. R. R. Clarke, M.B., B.S., F.R.C.S. \\ G. F. Rowbotham, B.Sc., L.R.C.P., F.R.C.S. \\ From the Regional Neurological Centre, Newcastle upon Tyne
}

IN the early stages after head injury, continuous and unremitting care is essential. This is demanding in terms of time and facilities but can be a source of great interest and satisfaction to the surgeon. For treatment to be correct it is necessary for the aims of management constantly to be borne in mind (Gurdjian and Webster, 1958; Potter, $196 \mathrm{r}$ ). Most patients with head injuries will recover without operative intervention. In this first group the surgeon's task is to provide the conditions that will be conducive to a speedy and full recovery. At the opposite end of the scale are those whose condition is deteriorating, either from the direct effects of the injury or from secondarily developing states. Here the problem is to recognize the cause of deterioration and, when possible, to reverse the unfavourable trend without delay. The third group consists of patients who neither improve nor become worse and here too the surgeon must make a diagnosis and institute suitable treatment.

When the patient first comes under medical care an accurate history should be obtained, if necessary from eye-witnesses, family members and those who have brought the patient to hospital. Past medical history and the state of health at the time of the accident must be investigated, for these may have a bearing on the cause of the injury and the actual physical state of the patient; illnesses such as coronary artery disease and diabetes mellitus are relatively common amongst those admitted to accident units. The time of the accident and any alterations in conscious state or behaviour should be entered clearly on the case record. From the time of arrival at hospital continuous observation must be maintained and a thorough examination of the patient in a good light is required. Examinations of the central nervous system, abdomen and thorax are essential and the blood-pressure, pulse rate, respiration rate and temperature, with details of the size and reactions of the pupils, should be recorded at least as often as every half-hour at first. The value of accurate, legible, concise and complete records cannot be overstressed.

\section{Care of the Unconscious Patient \\ Provision of Airway}

Obstruction of the upper respiratory passages from the tongue, blood, vomit or secretions is very apt to occur when consciousness and cough reflexes are depressed (Maciver, Frew and Matheson, 1958; Maciver, Lassman, Thomson and McLeod, 1958). To the injured brain even slight degrees of anoxia are dangerous and should be avoided by early attention to the airway. The patient should be placed in the three-quarters prone position so that the tongue will fall forward and fluid matter flow from the open mouth. Gentle suction is used to clear the air passages. It may be possible to use a mouth tube but this will need careful supervision to ensure that it does not become blocked or displaced. Should these simple measures not suffice, endotracheal ? intubation using a laryngoscope is indicated. If the jaws are tightly clenched, relaxant drugs can be used, provided that apparatus for pulmonary inflation is in readiness. An intratracheal tube should not be used for more than 36 hours because of the danger of laryngeal ulceration and infection. In certain circumstances tracheostomy should be considered but it must be borne in mind that this procedure carries its own risks and demands very high standards of nursing. The trachea harbours many organisms and the danger of dissemination of infection from a tracheostomy is great (Clarke, 1963). The type of patient who really benefits from a tracheostomy is the one who would normally be expected to recover from his brain injury were it not for the adverse effects of associated injuries or diseases. Examples of these are chest injuries, lung diseases, jaw injuries and fractures of the femur or pelvis where immobilization causes difficulty in the maintenance of a clear airway. Prolonged states of deep unconsciousness are often treated by tracheostomy but in our view the operation is better avoided whenever possible in these circumstances because of the danger of cross-infection and the undesirability of prolonging hopeless and distressing situations. 
In the prevention of lung complications skilled physiotherapy is invaluable and antibiotic cover should be provided in every case.

\section{The Control of Restlessness}

Patients may be restless for many reasons. While cerebral irritation and confusional states moy make control of the patient difficult, the discomfort of a distended bladder or the pain of a headache may be contributory causes of restlessness. In the early stages after head injury sedative drugs are best avoided and they should be given only when one feels absolutely sure that extradural or subdural hæmatomas are not present. Suitable drugs for use in these circumstances are either paraldehyde or a combination of a phenothiazine with pethidine.

More important than the use of drugs is the provision of really well-padded cot sides for the bed. A net is a useful device for restraining the patient who might otherwise climb over the bed sides or ends. Extreme restlessness may necessitate nursing on mattresses placed side to side on the floor.

\section{Care of the Skin}

Here the aim is to avoid chafing and the development of pressure sores. Care must be taken whenever the patient is moved. In practice this means that adequate man-power is available for lifting purposes. The skin should be kept clean, dried carefully and treated with barrier cream. The position of the patient in the bed should be changed hourly.

\section{The Bladder}

Incontinence of urine is usual but retention sometimes occurs, necessitating continuous catheter drainage and the use of a suitable sulphonamide to keep the urine sterile. A careful watch should be kept for bladder infection.

\section{The Bowels}

If these are not being moved satisfactorily an enema will be required every three days.

\section{Temperature Control}

\section{(Cooper and Ross, 1960)}

The aim here is the maintenance of normothermia. If the temperature rises above $100^{\circ} \mathrm{F} .\left(3^{\circ} \mathrm{C}\right.$.) measures should be taken to reduce it. To start with, the patient's clothing is removed and he is left with a sheet as the sole covering. If this is not enough, tepid sponging may be applied. Should the temperature continue to rise, air is blown across the naked body by electric fans. Any tendency to shiver may be controlled by the use of intramuscular injections of the "lytic cocktail' (chlorpromazine, phenergan an pethidine).

\section{Mouth, Eyes and Nose}

In states of prolonged unconsciousness thes $\overrightarrow{\vec{E}}$ will need regular toilet and the application of local antibiotics.

\section{Decerebrate Rigidity}

This commonly occurs in spasms, associated with hyperpnœa and often in response to peripheras stimulation. It may be brought under contro $\vec{\Phi}$ with 'lytic cocktail' but care must be exercised in the use of these drugs lest a dangerous fall if blood pressure is produced.

\section{Feeding}

If the patient is unable to swallow, a fine plastic stomach tube is passed and left in position There is, however, no need in the first 12 hoursy to administer fluids other than those require 6 to compensate for blood loss. During the second I 2 hours $2 \mathrm{oz}$. of water are given hourly and on the second and third days mixtures of 3 pints of water with 3 pints of milk and $300 \mathrm{~g}$. of glucose are administered during each 24 hours, giving $\$$ calorie value of 2,250 with $50 \mathrm{~g}$. of protein. Laterథ the diet is gradually enriched and made more sopd.

This basic scheme may require modificationsix the light of biochemical examination of the bloo When possible, daily estimations are made of the blood urea, sodium, potassium, chloride, and bicarbonate.

If the gastro-intestinal tract will not absori⿱ the quantities of fluid recommended, intravenous feeding will be necessary.

\section{The Complications of Head Injuries}

When damage to the brain has been over? whelmingly severe, recovery is impossible and the patient must sooner or later succumb to his. injuries. With lesser injuries there may be secondary occurrences that cause deterioration. or failure to recover consciousness. Some of these are amenable to treatment but early diagnosis and prompt treatment are essential if lives are to. be saved. The following lesions should be borne in mind.

Extradural Hamorrhage

(Hooper, 1959; McKissock, Taylor, Bloom and స్心 Till, r960)

In the early stages extradural hæmorrhage i probably the most important complication. If may follow a relatively minor injury. Leff untreated it will certainly lead to death. Bleeding into the extradural space usually occurs in the supratentorial portion of the head, generally 
in one temporal region. It can, however, take place in the posterior cranial fossa. The hæmorrhage is usually the result of a tear in a meningeal artery but it can follow injury to one of the dural venous sinuses or be the result of bleeding from the diploic venous channels. The clinical picture should be familiar to all (Lewin, 1949). Typically the patient is unconscious for a short while, recovers and then gradually loses consciousness again. Variations in this picture are not uncommon. For instance, the patient may not lose consciousness in the beginning but may gradually become drowsy and later unconscious. Alternanatively, he may never recover full consciousness after the blow has been received. The first sign that all is not well may be a convulsion. Neurological signs that may occur are weakness of one side of the body with an extensor plantar response. The classical alterations in the pupils described by Hutchinson may also be seen. When a pupil is dilated and does not contract on direct or consensual exposure to light a tentorial pressure cone is present. In the early stages of cerebral compression by extradural hæmorrhage the blood pressure rises and the pulse rate falls; the respiration becomes deep and slow. If the condition is not relieved by surgery the blood pressure falls, the pulse rate rises and the respirations become rapid and shallow. A rising temperature is an ominous sign. The most important indication of cerebral compression due to extradural hamorrhage is an alteration in the level of consciousness; on this sign alone the diagnosis can be made. The position of a hæmatoma may be deduced from the presence of surface bruising, radiological evidence of a fracture, and from the neurological signs. Once extradural hæmorrhage is suspected an immediate burr-hole exploration should be made. The site of the first burr-hole is determined by the physical signs. If the first exploration does not reveal a hæmatoma, further burr-holes will have to be made; thus both sides of the skull may have to be explored and in as many as four places. Should a hæmatoma be found it is rapidly exposed by a large craniotomy or craniectomy. After removal of the hæmatoma careful hæmostasis must be secured and the wound closed with drainage.

\section{Subdural Hamorrhage}

(McKissock, Richardson and Bloom, I960)

This may present in an acute, a subacute or a chronic form. It occurs as a result of a laceration of the surface of the brain, or the tearing of veins that run from the surface of the brain to the venous sinuses. When a hæmatoma follows a brain laceration it is naturally situated over the area of torn brain. When it results from rupture of a vein blood usually collects posteriorly over the occipital and parietal regions. Subdural hæmatomas are often bilateral. In the acute form a hæmatoma is nearly always associated with a severe brain injury. With subacute and chronic bleeding a patient's initial condition is much less serious. The presence of a subdural hæmatoma should be suspected when a patient's condition fails to improve with simple remedies or when the level of consciousness deteriorates. As in the case of extradural hæmorrhage, convulsions may occur. Should a patient remain conscious despite subdural bleeds he will often complain of severe headache and show signs of raised intracranial pressurepapillœdema, sixth nerve palsies, raised blood pressure and a slow pulse rate. Focal neurological signs such as hemiplegia are uncommon. Diagnosis is made by burr-hole exploration, which should always be carried out on both sides of the skull. The dura mater is opened and the hæmatoma is allowed to drain away. It is nearly always possible in this way to obtain satisfactory evacuation of the hæmatoma. Exceptionally a bone flap may have to be raised to permit a wide opening of the dura mater and evacuation of an adherent solid clot. However, such cases are rare and usually associated with severe brain damage.

\section{Subarachnoid Hamorrhage}

Bleeding into the subarachnoid space may occur from any vessel on the surface of the brain. Blood is then carried in the cerebrospinal fluid through the subarachnoid space and into the cisterns. Irritation of the meninges by blood causes vascular congestion, more bleeding and cerebral œdema. Arterial spasm may be provoked by subrachnoid hæmorrhage. Clinically, the condition is shown by headache, neck stiffness, Kernig's sign and, in the later stages, papillœdema. The diagnosis is made by lumbar puncture and examination of the cerebrospinal fluid. Subarachnoid hæmorrhage after head injury is treated by rest and analgesics.

When blood is found by lumbar puncture he history of the case should be reviewed and, if it is thought that the subarachnoid hæmorrhage may have preceded the injury, the patient should be transferred to a neurosurgical unit for angiography.

\section{Cerebral Hamorrhage}

Cerebral hæmorrhage may be caused by surface laceration of the brain with an extension of hæmorrhage into the deeper structures, or by rupture of a deeply placed cerebral vessel. It is usually a complication of a severe brain injury and the prognosis here is bad. Very occasionally an isolated hæmatoma may develop within the brain without any serious accompanying brain 
damage. Such a hæmatoma is susceptible to treatment. Clinically the picture is that of deterioration in the level of consciousness with localizing neurological signs and evidence of raised intracranial pressure. In many ways it mimics an extradural hæmorrhage. The treatment is burr-hole exploration over the suspected site and aspiration of the hæmatoma through a brain cannula.

\section{Cerebral Edema}

Edema is usually a complication of contusion of the brain and may occur early or late. It causes a deterioration in the level of consciousness and signs of raised intracranial pressure. It is impossible to diagnose the condition clinically with any certainty. Therefore, in the management of this condition the first essential is to carry out burr-hole exploration on each side. If no extradural or subdural hæmatoma is found, a cannula is passed into the brain through each burr-hole to determine whether an intracebral hæmatoma is present; if none is found and the brain appears to be swollen, a diagnosis of œdema can be made. The condition is treated firstly by the avoidance of overhydration of the patient and secondly by the application of dehydration methods. The most powerful dehydrating substances are urea (Stubbs and Pennybacker, 1960) which may be given intravenously in a dose of $\mathrm{Ig} / \mathrm{kg}$. of body weight, and mannitol which can also be administered as an intravenous infusion in the same dosage (Shenkin, Goluboff and Haft, 1962)

\section{Meningitis}

This condition can be fulminating in its onset, causing death within a few hours if not detected early and treated energetically. Its presence may be suspected if there is a source of infection such as an open wound, a septic lesion or a cerebrospinal fluid fistula into the nasal passages or ear. Meningitis usually causes neck stiffness, a positive Kernig's sign and a deteriorating level of consciousness. The diagnosis is made by lumbar puncture, which should never be omitted when meningitis is suspected. It is justifiable to give a general anæsthetic if this is necessary to perform the lumbar puncture and obtain a specimen of cerebrospinal fluid. The fluid must be sent to the laboratory for identification of the causal organisms and the performance of antibiotic sensitivity tests. When the fluid obtained by lumbar puncture appears turbid, an intrathecal injection of 5,000 to ro, 000 units of penicillin should be given and systemic treatment with antibiotics and chemotherapeutic agents is started at once. Penicillin should be given in large doses; if an adequate fluid intake can be ensured, a sulphonamide should be given as well because this freely passes the blood-brain barrier. Mods fications in the antibiotic treatment may have to be made in the light of response to treatment and the information obtained from the bacteriology laboratory. In serious cases daily intrathecal injections of penicillin will be required and streptomycin may also be given by this route considered necessary. Failure of the patier to respond to these measures is an indication for intraventricular antibotic treatment.

\section{Epilepsy \\ (Jennett, 1962)}

Epilepsy may occur in the acute or intermedia stages or as a late sequel to head injury. In some. patients a past history or a family history $\dot{\alpha}$ epilepsy may be obtained. As already mentioned fits may be a symptom of cerebral compressiow or of meningitis. They may, however, indicates actual brain damage. The fits must be broughe under control rapidly if deterioration is to be avoided but unfortunately most of the drugs which may be given for this purpose also depress the level of consciousness. Should drug treatment for epilepsy be necessary a doubly careful watc must therefore be kept for the development of other conditions that depress consciousness Phenytoin does not depress the level of conscions ness and can be given by the intramuscular:or intravenous route. If this is not effective in bringe ing the fits under control the best drug to use paraldehyde; this can be given by intramusculat injection in doses up to $10 \mathrm{ml}$. and the dose caf be frequently repeated.

\section{Cerebral Anoxia}

Anoxia often occurs when head injuries are associated with chest injuries and lung infections. Chest injuries of the flail or sucking type are especially liable to aggravate the cerebral condition. by reason of anoxia; the shallow breathing associ3. ated with simple fractures of the ribs may alsi. do so. Lung infections causing cerebral anoxiक are particularly liable to occur in patients whô have pre-existing pulmonary disease such aş bronchiectasis, asthma or chronic bronchitis. The diagnosis is based on the clinical picture and of radiographic examination of the chest. In this group of complications early tracheostomy can be life-saving. The treatment of flail injuries is also of great importance; paradoxical respiration is treated by the use of a cuffed tracheostom tube in connection with a respiratory pump after paralysis of the muscles of respiration wit鯆 curare-like drugs or by operative fixation of the injured parts of the chest wall. In these cases the advice of a thoracic surgeon is of great value $\vec{P}$ 
The administration of oxygen is helpful and all cases should be under full antibiotic cover.

\section{Special Investigations}

$X$-rays

Good radiographs of the skull should be taken as soon as possible after injury. It is usually most convenient for the patient to be examined radiographically on the way from the admission unit to the ward. Anteroposterior, Townes' and lateral views are required in every case. The particular points for which one should look in the radiographs are depressed fractures, fracture lines crossing the grooves in the skull produced by meningeal vessels, and fractures into the paranasal sinuses. If the pineal body is calcified its position in the A-P view should be noted, lateral displacement being indicative of a spaceoccupying lesion on the opposite side.

In the presence of signs of severe cerebral compression, immediate burr-hole exploration must be performed without delaying for radiological investigations unless these can be made within a few minutes.

\section{Burr-holes}

As already mentioned, burr-holes should be made when the patient's condition is deteriorating or is unsatisfactorily static, and particularly when a massive surface or intracerebral hæmorrhage is suspected. By means of inspection holes hæmatomas and æedema can be diagnosed with certainty. Specimens of cerebrospinal fluid may be obtained by cannulation of ventricles and penicillin or streptomycin can be injected into ventricles if the fluid is found to be purulent. The value of burr-hole exploration cannot be overstated; surgeons in charge of patients with head injuries should be prepared to perform the operation on the slightest suspicion of cerebral compression. Many lives which would otherwise be lost can be saved if this policy is adopted.

\section{Lumbar Puncture}

Lumbar puncture is seldom indicated in the acute phases of head injury and may indeed be dangerous for it can precipitate the development of a tentorial or cerebellar pressure cone. However, it should be performed if there is evidence of meningeal irritation. Should blood be found in the cerebrospinal fluid this indicates subarachnoid hæmorrhage but it by no means excludes the presence of other pathological states such as extradural or subdural hæmatomas.

$\mathrm{X}$-rays, burr-holes and lumbar puncture are the only special investigations essential for the proper management of head injuries. Contrast X-ray studies (Alexander, 196r; Hancock, 196r), electroencephalography and echoencephalography (Jefferson, 1959) have their place in specialized 3

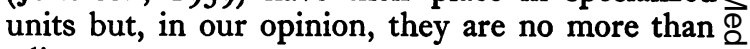
adjuncts.

\section{Points in General Operative Technique}

(Rowbotham, 1949; Rowbotham and Hammersley, 1953)

\section{Anasthesia}

A free airway at all times is essential in order $\stackrel{\overparen{D}}{\circ}$

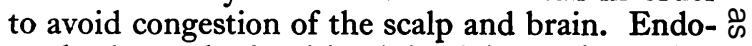
tracheal anæsthesia with minimal doses of anæsthe- $\overrightarrow{0}$ tic drugs and relaxants is advised. When good facilities for general anæsthesia are not available, $\bar{\omega}$ local anæsthesia with liberal quantities of lignocaine for infiltration of the scalp should be employed.

\section{Scalp Preparation}

The head should be meticulously shaved, care being taken to avoid injuring the skin. The scalp is then washed with soap and water, swabbed with perchloride solution and finally treated with chlorxylenol (e.g. Dettol). Spirit and iodine should be avoided as they are apt to scale or burn the skin.

\section{Positioning}

The head is supported on sandbags or fir pillows so that it is raised above the rest of the body. Obstruction to the veins of the neck muste be avoided. If local anæsthesia is being used the patient's wrists should be loosely secured and sheets should be pinned round the body.

\section{Apparatus}

Good lighting, efficient suction and diathermy are necessary. Without them the surgeon will sooner or later encounter unsurmountable difficulties.

\section{Hamostasis}

Hæmostasis must be perfect before the head is closed since bleeding within the skull will lead to cerebral compression.

The points set out above may seem trivial but the margin between success and failure in head surgery is extremely narrow. Success depends on meticulous attention to detail.

\section{Cerebrospinal Fluid Rhinorrhøa}

C.S.F. rhinorrhœa is caused by fistulæ from the subarachnoid space through the cribriform plate or into the paranasal sinuses. The patient should be instructed not to blow his nose. A cream of chlorhexidine and neomycin (e.g. Naseptin) is placed in the nostrils six-hourly and a sulphonamide should be administered. Although 
the C.S.F. leak will cease spontaneously in many cases, the danger of meningitis will remain; repair of the dura at a suitable time should be carried out. This is an operation requiring special skill and experience and is best not attempted unless it can be performed in a Neurosurgical Unit.

\section{Cerebrospinal Fluid Otorrhœa}

As in the case of C.S.F. rhinorrhœa the danger here is of meningitis or brain abscess; sulphonamides should be given. The external auditory meatus is cleaned carefully and a sterile pad is kept over the ear. Dural repair is rarely needed for this condition. Once the escape of fluid has ceased meningitis is unlikely to develop.

\section{Closed Fractures of the Skull}

A / fracture of the skull without depression of bony fragments requires no surgical treatment on its own account. In children, indented fractures, often without demonstrable fracture lines, may be seen. Here, the indications for surgical treatment are:

(I) At birth-large indentations associated with signs of cerebral compression.

(2) At three months-disfiguring indentations outside the hair line, indentations over the motor cortex and indentations associated with neurological deficits.

(3) At three years-all indentations more than one inch in diameter.

When elevation of an indented fracture is indicated it should be carried out by levering up the depressed bone with a curved dissector inserted through a trephine hole at the periphery of the indentation.

Closed depressed fractures are often unassociated with signs of brain damage and in such cases it may be wise to leave well alone, particularly if they are situated over large dural sinuses.

Indications for operation on depressed fractures are:

(I) Evidence of cerebral compression in an unconscious patient.

(2) Signs of underlying brain damage or persistent headache and giddiness.

(3) Penetration of the dura. Judgment on this can be based only on X-ray appearances of the shape of the fragments, angle of tilt and amount of depression.

(4) Cosmetic considerations.

If operation is performed, the fracture should be exposed by means of a scalp flap. Bony fragments must not be rocked out but should be picked out with bone forceps. When the fragments are tightly interlocked it may be best for a burr-hole to be sunk at the periphery of

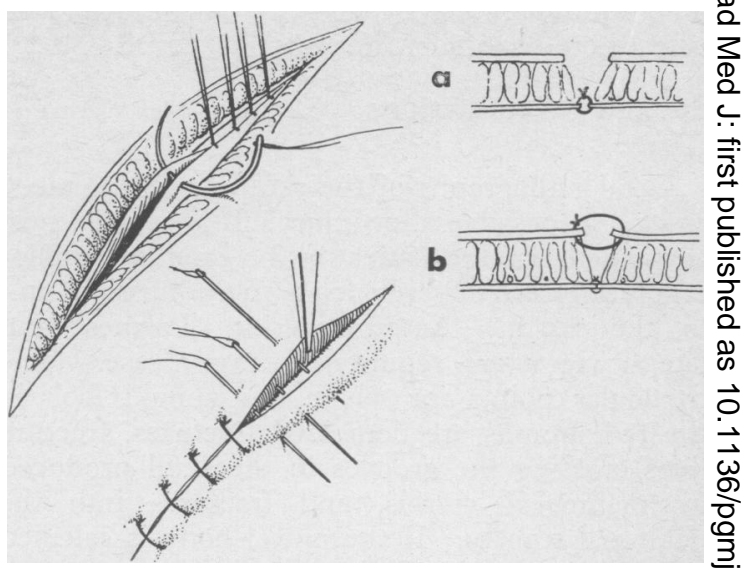

FIG. I.-Closure of scalp with interrupted silk sutures.

the fracture and for the bone to be nibbled away $\stackrel{\odot}{\varnothing}$ until a portion of the fracture is loose. Alternatively, a quadrilateral block of bone bearing the fracture may be cut out by means of Gigli saw cuts linking four burr-holes. The bone block ${ }^{\mathbb{D}}$ can then be remodelled manually before replacement.

\section{Open Wounds of the Head Scalp Wounds}

Excision of skin edges is unnecessary and liable to cause difficulty in wound closure. If the scalp tissues are dirty, they should be cleaned by scraping with a scalpel. During wound closure, $\stackrel{0}{2}$ the epicranial aponeurosis should first be sutured $\stackrel{\odot}{\triangle}$ with silk. The skin is then brought together with $\overrightarrow{\vec{F}}$ interrupted sutures of the same material (Fig. $\frac{3}{3}$ I). If the wound is contaminated or infected the layer of buried sutures is best omitted.

\section{Compound Fractures}

Loose fragments of bone are lifted out (Fig. $\frac{\dot{\sigma}}{3}$ 2) and the underlying dura is carefully inspected. for tears. If the bone is absolutely clean on $\frac{0}{3}$ inspection it may be replaced but, if there is any doubt regarding its cleanliness, it is best discarded 음 and a kranioplasty performed at a later date.

\section{Dural Tears}

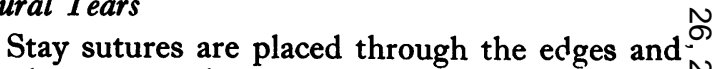
used to retract them so that the underlying brain may be inspected. If access is inadequate the $\mathrm{\omega}$ dural wound is extended. At the end of the opera- tion the dura should, in our opinion, be closed byco suture (Fig. 3). If there is any difficulty in $\Phi$ approximating the edges, a graft of fascia can be ${ }^{+}$ used to fill the gap. This fascia may be taken ${ }^{\circ}$ from the temporal regions or from the thigh. 


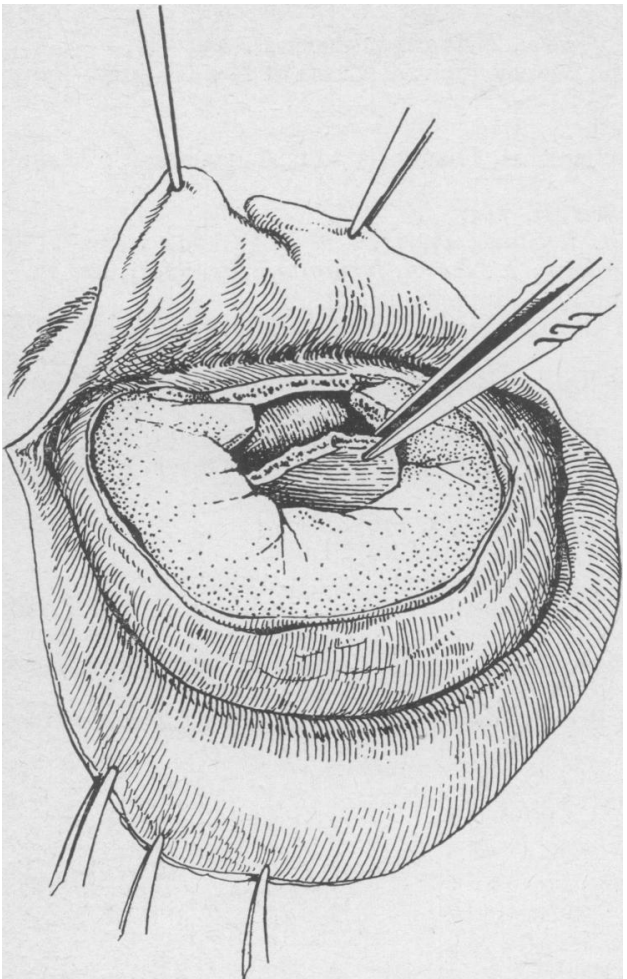

Fig. 2.-Removal of depressed bone fragment.

\section{Cerebral Wounds}

Here the aim is the removal of blood clots and dead tissue, the extraction of foreign bodies, and the arrest of hæmorrhage. All manœuvres must be made with the utmost gentleness; care should be taken to avoid damage to healthy tissue by heavy retraction or unnecessarily vigorous suction. Brain retractors applied over lintine swabs are used to expose the depths of brain wounds and debridement is performed by suction, using a fine glass tube as a nozzle (Fig. 4). A foreign body in a deep situation difficult of access should not be disturbed. It will only rarely lead to abscess formation or epilepsy. Hæmorrhage is arrested by electro-coagulation, the application of silver clips to vessels, muscle grafts or gelatine sponge.

When a dural venous sinus is torn, hæmorrhage may be torrential. Should the sinus be divided the ends must be clamped and ligated. A small tear can sometimes be closed by suture. Most injuries, however, will be large lateral tears and

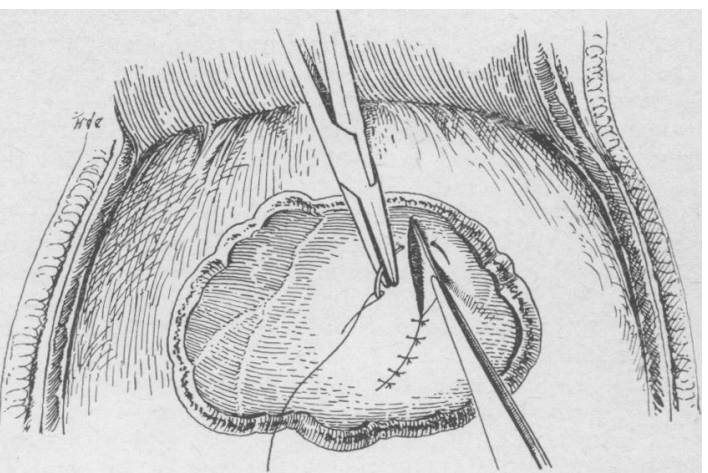

Fig. 3.-Dural closure with interrupted silk sutures.

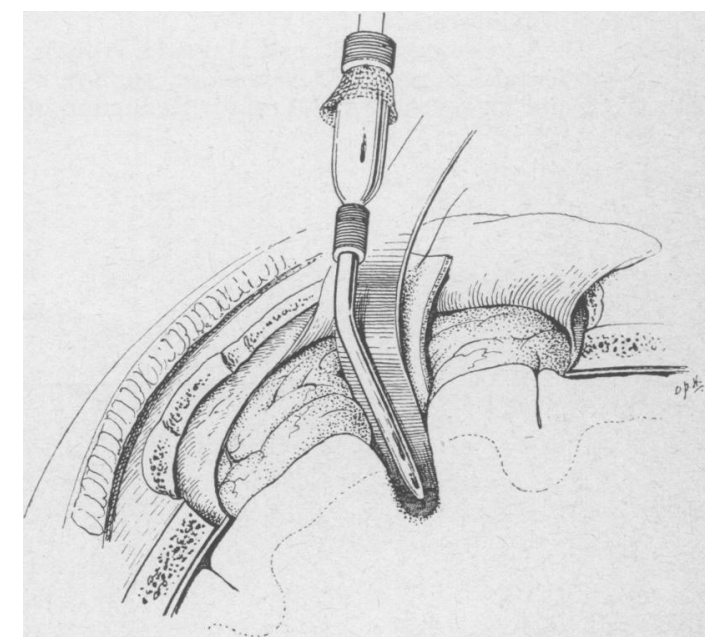

Fig. 4.-Debridement of brain wound.

these are best repaired by muscle grafts or packs of gelatine foam. The repair material is placed firmly on the sinus tear and a swab is laid over it. Suction is then applied to the swab until bleeding stops.

Finally, it must be reiterated that success depends on attention to detail. General surgical principles should be followed throughout. Blood for transfusion must be readily available whenever operation is performed for any wound extending deeper than the scalp.

We wish to thank Dr. Robert Blowers for help with the manuscript and Mrs. V. L. Robinson for secretarial assistance. 


\section{REFERENCES}

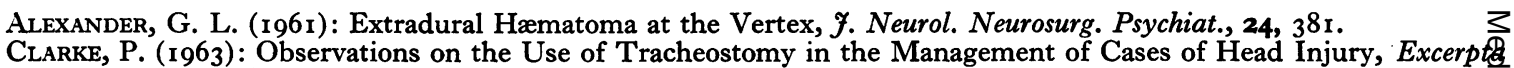
med. (Amst.), 60, 107.

Cooper, K., and Ross, D. (1960): 'Hypothermia'. London: Cassell.

GURDJIAN, E. S., and Webster, J. E. (1958): 'Head Injuries, Mechanisms, Diagnosis and Management'. Londo J. \& A. Churchill.

Hancock, D. O. (196I): Angiography in Acute Head Injuries, Lancet, ii, 745.

HOOPER, R. (1959): Observations on Extradural Hæmorrhage, Brit. Y. Surg., 47, 71.

Jefrerson, A. A. (1959): Some Experiences with Echo-encephalography, F. Neurol. Neurosurg. Psychiat., 22, 83.

JENNETT, W. B. (1962): 'Epilepsy After Blunt Head Injuries'. London: Heinemann.

LEwIN, W. (1949): Acute Subdural and Extradural Hæmatoma in Closed Head Injuries, Ann. roy. Coll. Surg. Eng $5,240$.

Maciver, I. N., Frew, I. J. C., and Matheson, J. G. (1958): The Role of Respiratory Insufficiency in the Mortalit方 of Severe Head Injuries, Lancet, ii, 390.

, Lassman, L. P., Thomson, C. W., and McLeod, I. (1958): Treatment of Severe Head Injuries, Ibid., ii, 544.

McKissock, W., TAYLOR, J. C., Bloom, W. H., and Till, K. (1960): Extradural Hæmatoma: Observations on $12 \mathrm{~g}$ Cases, Ibid., ii, 167.

, Richardson, A., and Bloom, W. H. (1960): Subdural Hæmatomas, Ibid., i, 1365.

PotTer, J. M. (196r): 'The Practical Management of Head Injuries'. London: Lloyd Luke.

Rowbotham, G. F. (I949): 'Acute Injuries of the Head'. Edinburgh and London: E. \& S. Livingstone. , and HAMmersLeY, D. P. (1953): 'Pictorial Introduction to Neurological Surgery'. Edinburgh and London
E. \& S. Livingstone.

Shenkin, H. A., Goluboff, B., and HAFT, H. (1962): The Use of Mannitol for the Reduction of Intracranial Pressuree in Intracranial Surgery, $\mathcal{F}$. Neurosurg., 19, 897.

StubBs, J., and PenNYBaCKER, J. (1960): Reduction of Intracranial Pressur ewith Hypertonic Urea, Lancet, i, ro94. 